\title{
SISTEMAS DE PREPARO DO SOLO PARA AS CULTURAS DE SOJA E TRIGO ${ }^{(1)}$
}

GASTÃo MORAES DA SILVEIRA (2), Divisão de Engenharia Agrícola, ANTONIO WILSON PENTEADO FERREIRA FILHO, JOSE GUILHERME DE FREITAS (2), Escritório Regional de Assis, Secão de Arroz e Cereais de Inverno, JOSE ANTONIO JORGE (2), Secāo de Pedologia, e VIOLETA NAGAI (2), Secão de Técnica Experimental e Cálculo, Instituto Agronómico.

\section{RESUMO}

No presente trabalho estudaram-se dois processos de semeadura, a direta e a convencional, para as culturas de soja (Glycine max (L.) Merrill) e trigo (Triticum aestivum L.) plantadas num mesmo ano. Enfase especial foi dada ao problema das máquinas utilizadas nos dois sistemas de semeadura, caracterizando-se os diversos parâmetros envolvidos. Montou-se um ensaio de campo na Fazenda Canadá, municipio de Assis, no periodo 1979-82, com três safras para as duas culturas. Para o trigo, os tratamentos foram: preparo convencional (grade pesada e grade niveladora) e semeadura direta. Para a soja: convencional mais escarificação; convencional; aração e gradeação; aração e gradeação mais escarificação e semeadura direta. Os resultados mostraram que a interação entre os tratamentos aplicados numa cultura e os aplicados na cultura seguinte não foi significativa, não havendo também influência de preparo de solo para soja sobre a produção de trigo, exceto no ano agrícola 1981/82, em que as produções de soja sofreram influência. do tipo de preparo de solo para a semeadura do trigo. A economia de combustivel foi bastante significativa na semeadura direta das duas culturas. As máquinas para semeadura direta devem ser articuladas para que possam acompanhar as irregularidades do terreno.

(1) Os autores agradecem ao proprietário da Fazenda Canadá, Sr. Mauro Cândido de Souza Dias, e ao Eng甲-Agr. Dorival Finotti, a colaboração prestada durante os ensaios de campo. Recebido para publicação a 6 de junho de 1983.

(2) Com bolsa de suplementação do CNPq. 


\section{INTRODUÇÃO}

As culturas de soja e de trigo, embora com caracteristicas bastante diferenciadas, são de grande importância para a economia brasileira. Enquanto mais da metade do trigo consumido ainda é importado, o Brasil ocupa posição proeminente em relação à soja, que, encontrando estabilidade ecológica, atingiu níveis de produção satisfatórios. $\mathrm{O}$ mesmo não ocorre com o trigo, que é cultivado num período de menor índice pluviométrico, havendo necessidade de aproveitar o máximo da água disponivel armazenada no solo.

Atualmente está sendo estudada uma série de máquinas, implementos e suas combinações, visando a baixo consumo de energia e reduzidos efeitos nocivos sobre o solo, de modo a obter melhores condições para que o ecossistema solo-planta produza economicamente.

Os objetivos do presente trabalho são: a) estudar a combinação de diversos implementos visando ao melhor preparo do solo nas culturas de soja e trigo, relacionando-os com a produção; b) determinar, para os vários tratamentos, o rendimento de trabalho, isto é: capacidade teórica e efetiva e coeficiente de eficiência das máquinas nas diversas operaçōes; c) procurar a melhor regulagem dos equipamentos visando à máxima capacidade de trabalho; d) medir as características relativas às diversas máquinas, relacionando-as com a sua operação, como: profundidade de trabalho, largura de operação, velocidade de deslocamento, e e) determinar o consumo de combustivel.

FREE (2) aponta três principais sistemas de preparo do solo: a) convencional: consiste em aração, gradeação, riscagem do terreno e cultivos subseqüentes necessários para o controle do mato; b) cultivo mínimo ou reduzido: sistema em que as máquinas convencionais são usadas, porém as operações de revolvimento do solo são diminuídas; c) semeadura sem preparo: definida como sendo o mínimo possível de manipulação do solo para uma semeadura satisfatória, germinação, stand, crescimento e produção da cultura.

A semeadura direta, a mais nova técnica para preparo reduzido do solo (SHEAR \& MOSCHLER, 6) consiste em: a) eliminação da vegetação existente com um herbicida de contato ou dessecante: b) semeadura e colocação de fertilizante, movimentando o solo o mínimo possiveí; c) colheita.

PRICE (5) assim descreve o conceito de semeadura direta: na época da semeadura, no solo não-arado, aplica-se um herbicida de contato e, dias depois, utiliza-se um equipamento que abre o sulco de 5 a $10 \mathrm{~cm}$ de largura, onde é depositada a semente e o fertilizante. Nessas condiçōes, o solo é movimentado o mínimo possível.

O sistema de semeadura direta, comparado com o convencional, apresenta uma série de vantagens: controla a erosão (MONDARDO \& 
BISCAIA, 3) e economiza combustível (WILES \& KIEVIT, 8); utiliza um numero menor de máquinas e menor quantidade de mão-de-obra; retém a umidade do solo; permite um ganho de temperatura para semeadura e melhor emergência e desenvolvimento inicial das plantas (MUZILLI, 4).

Suas principais desvantagens são: alto custo dos herbicidas, dificuldades no controle das ervas daninhas (ALMEIDA, 1), maquinaria nāo apropriada (MUZILLI, 4) .

No que diz respeito à produção, tudo indica, no trigo, que nos anos mais secos é maior com a semeadura direta, e nos anos mais úmidos com o convencional (SOUZA \& MELO, 7), enquanto na soja parece não haver diferença de produção entre os dois sistemas de semeadura (NUZILLI, 4).

\section{MATERIAL E MÉTODOS}

Nas condições do presente trabalho, considera-se como preparc convencional todo aquele que revolve intensamente a superfície do solo com o uso do arado mais grade niveladora ou grade pesada e grade niveladora, os dois últimos mais utilizados na região. $O$ arado está em desuso devido à sua menor capacidade de trabalho.

\subsection{Ensaio de campo}

O experimento, em blocos ao acaso com seis repetições em parcelas subdivididas, foi instalado na Fazenda Canadá, município de Assis (SP), com a cultura do trigo, em abril de 1979, semeando-se posteriormente a soja. Os tratamentos relativos à soja foram estudados nos canteiros grandes (parcelas) e, os relativos ao trigo, nos pequenos (subparcelas). Os trabalhos se desenvolveram no periodo $1979 / 82$, com trés safras para as duas culturas.

Na cultura do trigo, foram empregadas as variedades: LA 14-34, originária de CIMMYT, em 1979, e a BH 1146, do Instituto Agronômico de Minas Gerais (já extinto) em 1980 e 1981. Os tratamentos constaram de preparo convencional (grade pesada e grade niveladora) e semeadura direta. Para a soja, foi utilizada a variedade Bossier nos três anos, empregando-se os seguintes tratamentos: convencional mais escarificação; convencional; aração e gradeação; aração e gradeação mais escarificação, e semeadura direta.

Como a soja é semeada logo após a colheita do trigo, as mesmas parcelas apresentavam as seguintes combinações de tratamentos por repetição:

I. Trigo: grade pesada e grade niveladora;

Soja: escarificação mais grade pesada e grade niveladora; 
II. Trigo: semeadura direta;

Soja: escarificação mais grade pesada e grade niveladora.

III. Trigo: grade pesada e grade niveladora;

Soja: grade pesada e grade niveladora.

IV. Trigo: semeadura direta;

Soja: grade pesada e grade niveladora.

V. Trigo: grade pesada e grade niveladora;

Soja: escarificação mais arado de disco e grade niveladora.

VI. Trigo: semeadura direta;

Soja: escarificação mais arado de disco e grade niveladora.

VII. Trigo: grade pesada e grade niveladora;

Soja: arado de disco e grade niveladora;

VIII. Trigo: semeadura direta;

Soja: arado de disco e grade niveladora;

IX. Trigo: grade pesada e grade niveladora;

Soja: semeadura direta.

$\mathrm{X}$. Trigo: semeadura direta;

Soja: semeadura direta.

Cada parcela era constituída de $50 \mathrm{~m}$ de comprimento por $20 \mathrm{~m}$ de largura, com área de $1.000 \mathrm{~m}^{2}$. Foi deixada uma bordadura de $5 \mathrm{~m}$ de cada lado da parcela, para passagem das máquinas, sendo uma área útil de $40 \mathrm{~m}$ de comprimento e $10 \mathrm{~m}$ de largura ou $400 \mathrm{~m}^{2}$. A colheita para avaliação de efeito de tratamentos foi feita em três áreas de $7 \mathrm{~m}^{2}$ por parcela.

Os dados relativos à produção de 1979 foram analisados segundo modelo para blocos ao acaso e, a dos demais anos, considerando o esquema em parcelas subdivididas.

A significância do contraste plantio direto versus plantio convencional de trigo foi verificada pelo teste $F$.

A área onde foi montado o experimento já vinha sendo semeada com o binômio soja-trigo, no sistema de semeadura direta havia dois anos. Notou-se uma camada adensada a $20 \mathrm{~cm}$ de profundidade: daí a opção pela escarificação, cujo objetivo era quebrá-la, verificando sua influência na produção.

A capacidade teórica e efetiva e o coeficiente de eficiência das máquinas foram determinados para as condições de trabalho no campo em operações normais da Fazenda Canadá. Seus valores não constam do quadro 7 , pois para soja a Canadá só vinha fazendo a semeadura direta. 


\subsection{Máquinas utilizadas}

1) Arado de discos acoplado ao sistema de levantamento hidráulico por três pontos do trator, sendo os bordos dos discos lisos e o diâmetro de 28 polegadas. Quanto ao número, usaram-se três discos em terreno bruto, e cinco quando a aração foi precedida de uma escarificação.

2) Grade pesada de arrasto com 20 discos de 26 polegadas de diâmetro, com dois corpos, sendo os discos da seção dianteira recortados e, os da traseira, lisos.

3) Grade niveladora com 41 discos de 18 polegadas de diâmetro, tendo dois corpos, sendo os discos da seção dianteira recortados e, os da traseira, lisos.

4) Arado tipo cinzel, popularmente denominado pé-de-pato ou subsolador, usado na escarificação: montado no engate de três pontos do trator, tem duas barras porta-ferramentas, paralelas e perpendiculares ao sentido de deslocamento, onde são montadas cinco hastes verticais rígidas, em cujas extremidades se fixam os órgãos com formato que lembra um pé de pato.

5) Pulverizador: equipamento de barra acoplado ao engate de très pontos do trator, com tanque com 500 litros de capacidade, empregado na pulverização, tanto de herbicida como de inseticida e fungicida: o número de bicos variou de 14 a $28 \mathrm{em}$ leque ou cone, de acordo com a finalidade.

6) Semeadora-adubadora de arrasto com linhas conjugadas, adotada na semeadura convencional: no trigo, utilizaram-se dezesseis linhas espaçadas de $18 \mathrm{~cm}$; na soja, seis linhas espaçadas de $54 \mathrm{~cm}$.

7) Equipamento dotado de enxada rotativa que prepara o solo apenas na linha de semeadura, efetuando ao mesmo tempo as operações de adubação e semeadura, para a semeadura direta. O conjunto é rígido no sentido transversal do terreno, dificultando o acompanhamento das irregularidades do solo. No trigo empregaram-se treze linhas espaçadas de $17 \mathrm{~cm}$ e, na soja, cinco linhas espaçadas de $51 \mathrm{~cm}$.

8) Máquinas automotrizes com largura de trabalho de $3,55 \mathrm{~m}$ e potência no motor de $94 \mathrm{cv}$, para a colheita.

9) Dois modelos de tratores: um com potência no motor de $92 \mathrm{cv}$ para as seguintes operações: aração, gradeação, escarifícação e semeadura direta. O outro, com $62 \mathrm{cv}$ em: aplicação de herbicida, semeadura convencional e pulverização.

\subsection{Métodos de trabalho e condução da cultura}

\subsubsection{Trigo}

O preparo convencional constou de uma passada de grade pesada e duas de niveladora. Os dados de adubação e semeadura para os dois sistemas constam do quadro 1. 


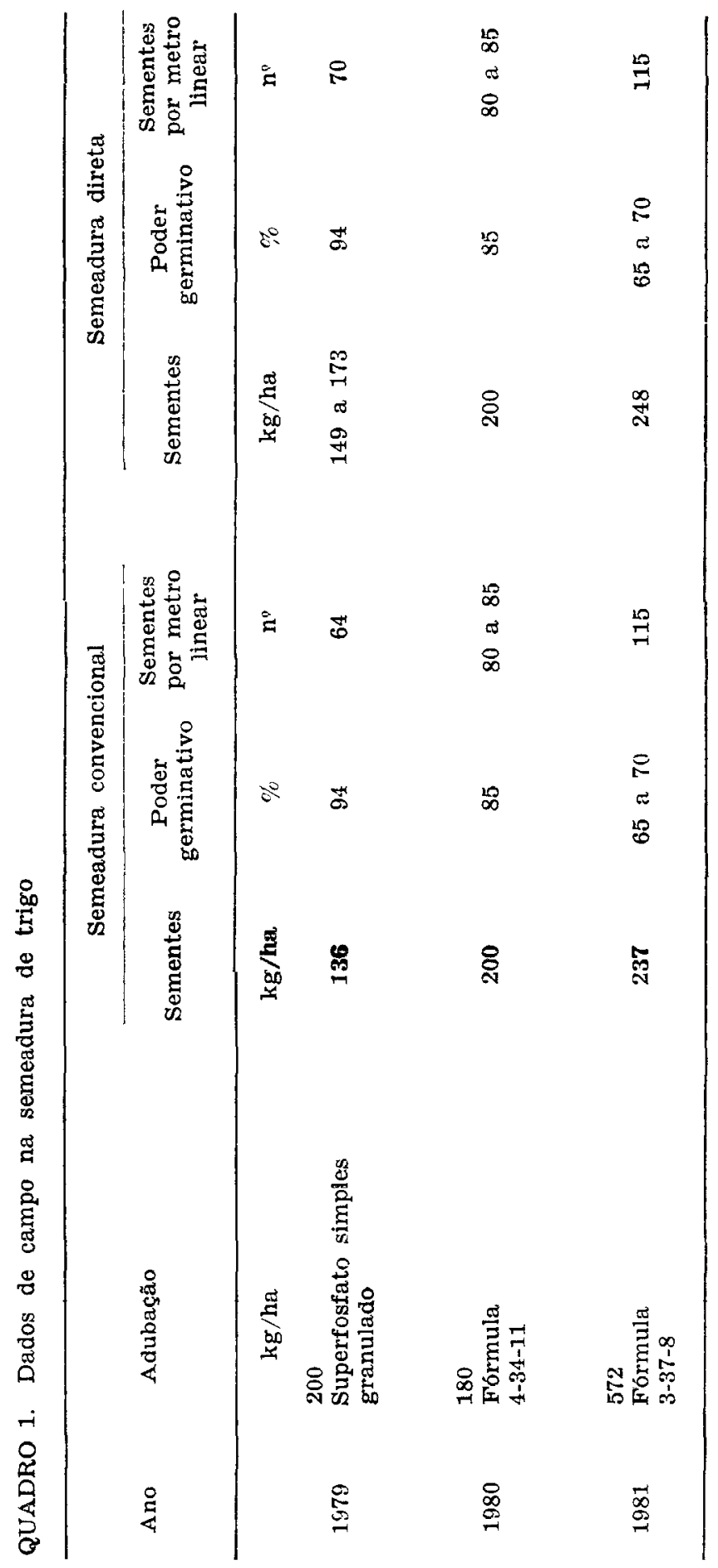

Bragantia, Campinas, 43(2):493-507, 1984 
Como tratos culturais para o trigo, nos dois sistemas, foram feitas aplicacões de fungicida, na base de $0,5 \mathrm{~kg}$ de Triadimefon e $2,5 \mathrm{~kg}$ de Maneb ativado por hectare, em três aplicações (45, 60 e 75 dias após a emergência das plantas).

Na semeadura direta do trigo, foram usados os herbicidas: Paraquat, na dose de 3,0 litros/hectare, e glifosate de 3,5 a 5,0 litros/hectare antes da semeadura.

Para controle de ervas daninhas, 25 dias após a emergência da planta de trigo, foi feita uma aplicação de 1,5 litro de $2,4 \mathrm{D}$ mais MCPA/hectare. As sementes de trigo também foran tratadas para evitar pragas de solo.

\subsubsection{Soja}

Para a soja, houve diversos tipos de preparo convencional: uso de araỏo cinzel para escarificação e grade pesada; grade pesada; arado cinzel e arado de disco; arado de disco. Posteriormente, em todos esses tratamentos, foi feita uma passada de grade niveladora, para destorroar e nivelar o terreno.

Em todos os tratamentos do preparo convencional, o controle de ervas daninhas foi realizado com a aplicação de trifluralina na dosagem de 2,5 litros/hectare em pré-semeadura incorporada.

$\mathrm{Na}$ semeadura direta foi efetuada uma aplicação de herbicida Paraquat na dosagem de 3,5 litros/hectare em 1979 e glifosate na dosagem de 3,5 e 5,0 litros/hectare em 1980 e em 1981 respectivamente.

Nos dois sistemas de cultivo foram realizados tratamentos das sementes, evitando, assim, pragas de solo. Antes da semeadura, as sementes de soja foram inoculadas.

A adubação nos três anos constou da aplicação de fósforo e potássio, gastando-se $280 \mathrm{~kg} /$ ha da fôrmula 00-30-15 de N, P e K.

As quantidades de sementes e respectivas densidades de plantio para os dois sistemas de semeadura constam do quadro 2. Foram também realizadas pulverizações para o controle de pragas na parte aérea da soja.

QUADRO 2. Dados de campo na semeadura da soja

\begin{tabular}{|c|c|c|c|c|}
\hline \multirow[b]{2}{*}{ Ano } & \multicolumn{2}{|c|}{ Semeadura convencional } & \multicolumn{2}{|c|}{ Semeadura direta } \\
\hline & Sementes & $\begin{array}{l}\text { Sementes } \\
\text { por metro } \\
\text { linear }\end{array}$ & Sementes & $\begin{array}{l}\text { Sementes } \\
\text { por metro } \\
\text { linear }\end{array}$ \\
\hline & $\mathrm{kg} / \mathrm{ha}$ & $\mathbf{n}^{2}$ & $\mathrm{~kg} / \mathrm{ha}$ & $\mathrm{n}^{9}$ \\
\hline $1979 / 80$ & 103 & 38 ou 26 & 104 & 38 ou 26 \\
\hline $1980 / 81$ & 86 & 28 & 86 & 28 \\
\hline $1981 / 82$ & 125 & 30 a 35 & 135 & 30 a 35 \\
\hline
\end{tabular}




\section{RESULTADOS E DISCUSSÃO}

Referem-se aos dados de produção de trigo para os anos de 1979, 1980 e 1981, enquanto para soja dizem respeito aos agricolas 1979/80, 1980/81 e 1981/82. Os dados de produção são relativos ao peso em gramas por $7 \mathrm{~m}^{2}$.

Os resultados da análise de variância mostraram que a interaçāo entre os tratamentos aplicados numa cultura e os aplicados na cultura seguinte não foi significativa, não havendo também influência de preparo do solo para soja sobre a produção de trigo. Entretanto, em 1981 as produçōes de soja foram superiores nas parcelas onde havia sido feita a semeadura convencional para $o$ trigo.

O quadro 3 apresenta as médias de produção de trigo nos diferentes anos e o coeficiente de variação de cada ano em estudo, e os quadros 4 e 5 , os dados médios operacionais respectivamente da semeadura convencional e da direta.

QUADRo 3. Médias (1) de produção de trigo para os diferentes tratamentos e anos

\begin{tabular}{|c|c|c|c|}
\hline \multirow{2}{*}{ Tratamentos } & \multicolumn{3}{|c|}{ Anos } \\
\hline & 1979 & 1980 & 1981 \\
\hline & & \multicolumn{2}{|c|}{ gramas $/ 7 \mathrm{~m}^{2}$} \\
\hline Semeadura convencional & $717 a$ & $650 \mathrm{a}$ & $248 \mathrm{~b}$ \\
\hline Semeadura direta & $692 a$ & $492 b$ & $274 a$ \\
\hline C.V. $(\%)$ & 15,3 & $\mathbf{1 5 , 1}$ & 15,8 \\
\hline
\end{tabular}

(1) Médias de tratamentos seguidas da mesma letra não diferem entre si.

Pelos dados do quadro 3, pode-se observar que, em 1979, não houve diferença entre os tratamentos semeadura convencional e direta. Já em 1980, a semeadura convencional resultou em maior produção. Contudo, em 1981, a direta foi superior. Esses resultados estão de acordo com as observações de SOUZA \& MELO ( $\boldsymbol{\gamma})$, uma vez que o ano de 1980 foi mais úmido e o de 1981, mais seco.

No quadro 6 encontram-se as médias de produção de soja no periodo agricola $1979 / 80$ a $81 / 82$, e, nos quadros 7 e 8 , os dados médios operacionais respectivamente para as semeaduras convencional e direta no mesmo período. 


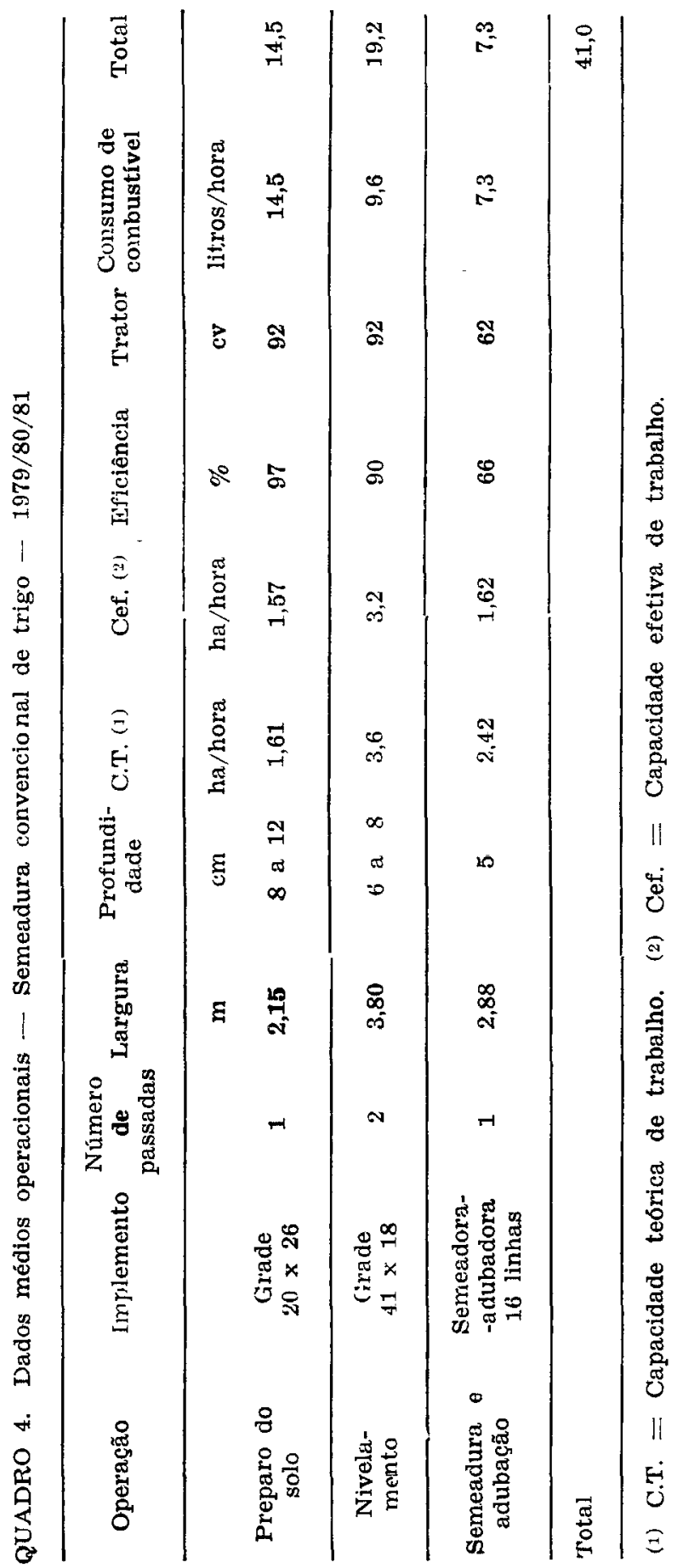




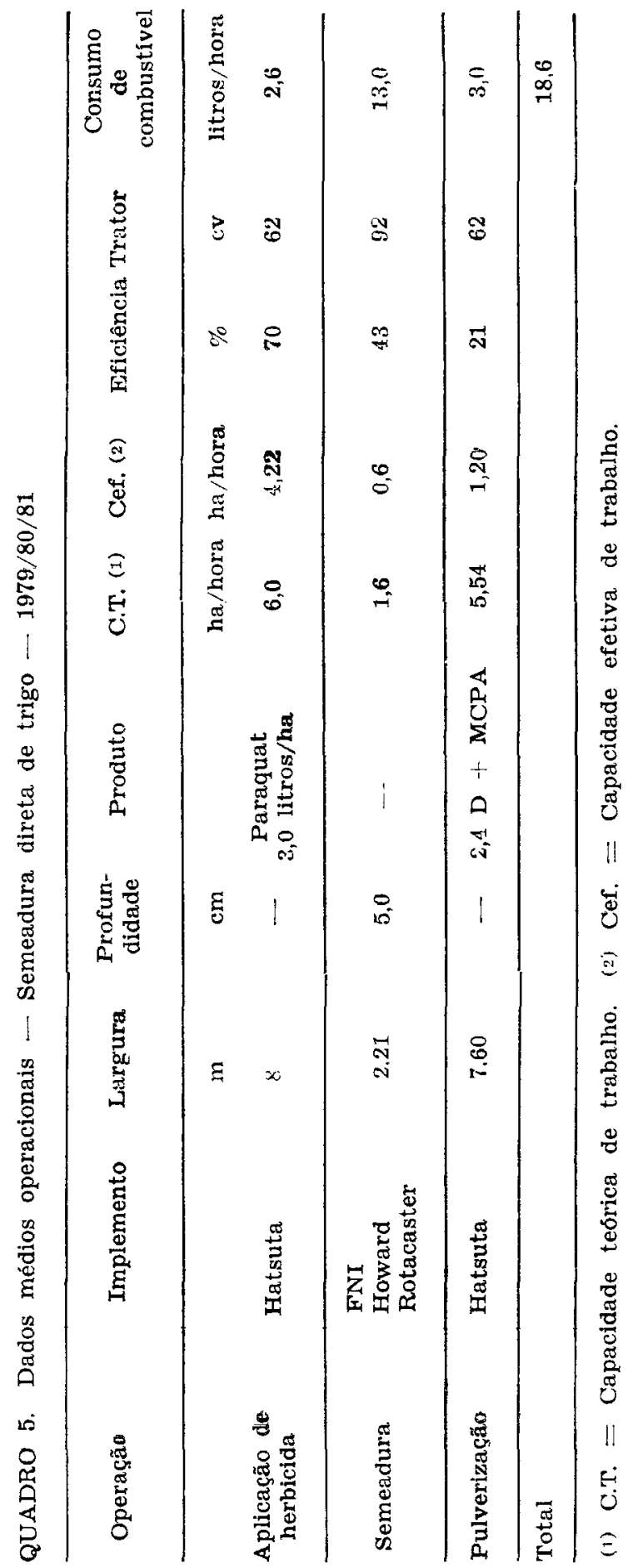


Tanto na cultura do trigo como na da soja, observando-se os quadros 4, 5, 7 e 8, há uma sensivel economia de combustível, mais da metade, na semeadura direta em relação à convencional, confirmando as observaçōes de WILES \& KIEVIT (8).

QUADRO 6. Médias de produção de soja relativas aos diferentes tratamentos e anos estudados. Coeficientes de variação (C.V.) relativos aos erros utilizados na comparação de médias

\begin{tabular}{lcccc}
\hline \multicolumn{1}{c}{ Tratamentos } & \multicolumn{3}{c}{ Anos } \\
\cline { 2 - 4 } & $1979 / 80$ & $1980 / 81$ & $1981 / 82$ \\
\hline & & gramas $/ 7 \mathrm{~m}=$ & - \\
& & 1.638 & 955 & 1.517 \\
Escarificação, grade pesada e grade niveladora & 1.673 & 1.067 & 1.580 \\
Grade pesada e grade niveladora & & & \\
Escarificação mais arado de & 1.587 & 935 & 1.631 \\
$\quad$ disco e grade niveladora & 1.647 & 952 & 1.579 \\
Arado de disco e grade niveladora & 1.666 & 982 & 1.591 \\
Semeadura direta & 12,7 & 28,9 & 10,5 \\
\hline C.V. (\%) & & & \\
\hline
\end{tabular}

Nas duas culturas, durante a condução dos trabalhos, houve certa dificuldade no controle das ervas daninhas na semeadura direta, confirmando as cbservaçôes de ALMEIDA (1). Principalmente na soja, a aplicação de herbicidas foi insuficiente, exigindo complementação com capina.

Quanto à maquinaria, o equipamento de semeadura direta, sendo rígido no sentido transversal do terreno, em locais irregulares deixou muitas sementes na superfície do solo, diminuindo o stand na emergência das plântulas. Em trabalhos futuros, aconselha-se o uso de máquinas articuladas, que acompanhem as irregularidades do terreno. Assim, o equipamento deve ser aperfeiçoado, o que de certa forma confirma MUZILLI (4).

Outro ponto observado durante os trabalhos é que a mão-de-obra não qualificada dificulta o uso da semeadura direta, por ser um processo muito sofisticado. 


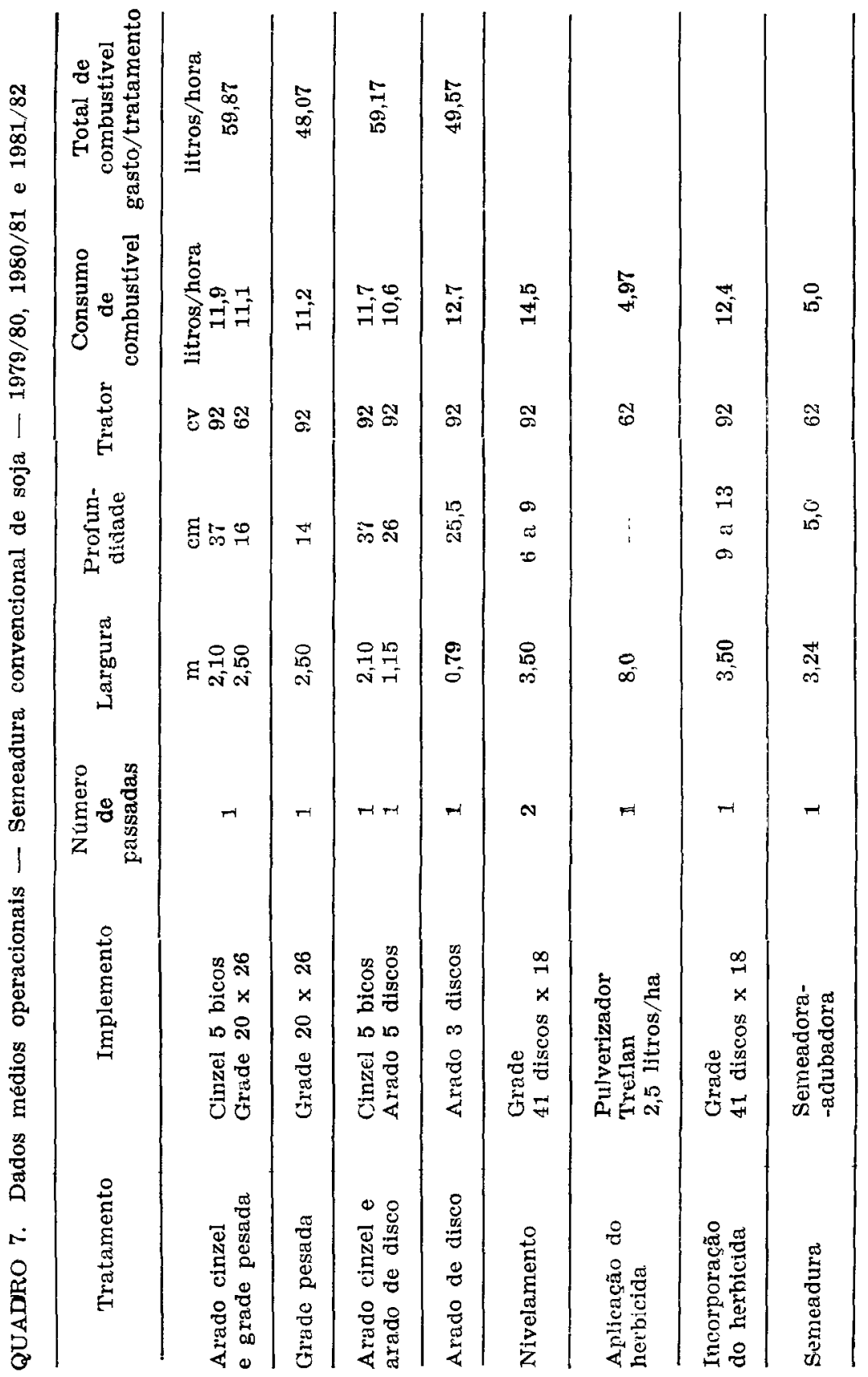




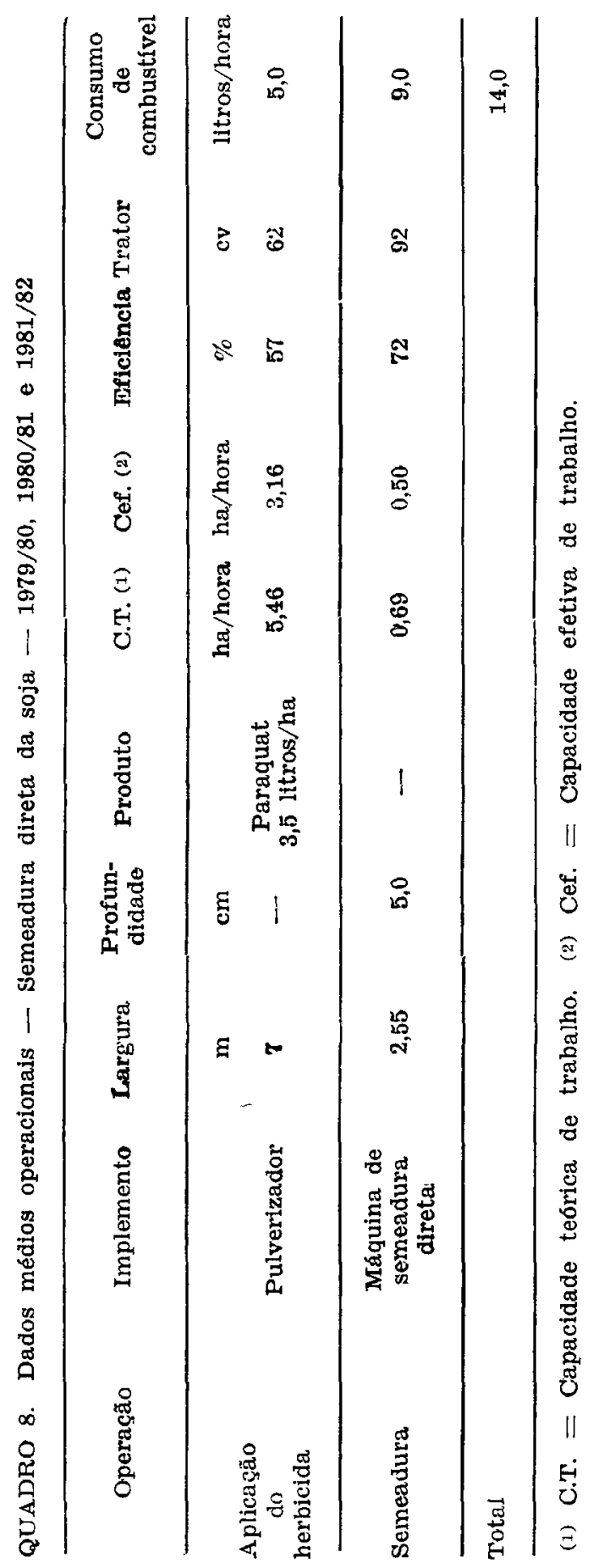

Bragantia, Campinas, 43(2):493-507, 1984 


\section{CONCLUSõES}

1. A semeadura de soja foi feita, utilizando-se qualquer um dos tratamentos empregados.

2. As produções de soja no ano agrícola 1981/82 sofreram influência do tipo de preparo de solo para semeadura de trigo. A semeadura convencional de trigo resultou em produções de soja superiores às obtidas com a semeadura direta.

3. No trigo, não houve diferença entre os tratamentos no ano de 1979. Em 1980, a semeadura convencional resultou em rnaiores produções que a direta, sendo significativa a diferença entre as médias, e em 1981, a semeadura direta foi superior, sugerindo-se paia o trigo essa semeadura nos anos secos.

4. Em nenhum dos anos houve influência de preparo do solo para soja, sobre a produção de trigo.

5. A economia de combustivel foi bastante significativa na semeadura direta nas duas culturas.

6. A eficiência de trabalho da semeadora no tratamento convencional foi superior à direta para a cultura do trigo, sendo a direta mais demorada.

7. O uso do arado cinzel na escarificação sistemática não trouxe os resultados esperados, no que diz respeito à produşão, aumentando também o consumo de combustivel.

\section{SUMMARY \\ TILLAGE MANAGEMENT PRACTICES IN SOYBEAN WHEAT DOUBLE CROPPING}

In a field experiment set up in Assis county, State of São Paulo, Brazil, two seeding processes namely no-till and conventional tillage systems for soybean (Glycine max (L.) Merrill) and wheat (Triticum aestivum L.) (double cropping) were studied. Special emphasis was given to the different seeding machines. Three crop yields were obtained. For wheat the treatments were: conventional seeding (heavy disking and leveling disking) and no-till. For soybean we had: conventional seeding plus chiseling; conventional seeding; plowing and disking; plowing and disking plus scarifying and no-till. The results showed that the interaction among the treatments were not significant, and that the soil management for soybean did not affect the wheat production. Fuel saving was significant for both crops in the no-till system. Machine articulation was essential to fit the roughness of soil surface in no-till.

\section{REFERENCLAS BIBILGRATHCAS}

1. ALMEIDA, F.S. Controle de ervas. In: FUNDAÇÃO INSTITUTO AGRONÔMICO DO PARANÁ. Plantio direto no Estado do Paraná. Londrina, 1981. p.101-144. (Circular IAPAR, 23) 
2. FREE, G.R. Mulch tillage in New York. Soil Science Society of America. Proceedings, 17:165-170, 1953.

3. MONDARDO, A. \& BISCAIA, R.M. Controle da erosão. In: FUNDACAU INSTITUTO AGRONÓMICO DO PARANA. Plantio direto no Estado do Paraná. Londrina, 1981. p.33-42. (Circular IAPAR, 23)

4. MUZILLI, O. Cultura da soja. In: FUNDAÇÃO INSTITUTO AGRONÓMICO DO PARANA. Plantio direto no Estado do Paraná. Londrina, 1981. p.199-202. (Circular IAPAR, 23)

5. PRICE, V.J. Minimum tillage: looks like a winner. Soil Conservation, 38(3): 43-45, 1972.

6. SHEAR, G.M. \& MOSCHLER, W.W. Continuous corn by the no tillage and conventional tilled method. Agronomy Journal, 61:524-526, 1969.

7. SOUZA, M.A. \& MELO, J.C. Manejo e preparo do solo. Informe Agropecuário, Belo Horizonte, $5(50): 19-22,1979$.

8. WILES, J. \& KIEVIT, D.T.I. Rendimento de máquinas e consumo de combustivel no sistema de plantio direto comparado ao sistema convencional. In: SEMINARRIO NACIONAL DE PESQUISA DE SOJA, 1., Lonđrina, 1978. Anais. Londrina, EMBRAPA/CNPS, 1979. v. 2, p.363-371. 